\title{
Antibacterial Activity of Green Synthesis Silver Nanoparticles Using Some Wild Edible Plants Commonly Used in Al Baha, Saudi Arabia
}

\author{
Abdulaziz Yahya Al-Ghamdi \\ Department of Biology, Faculty of Science, Al Baha University, Al Baha, Saudi Arabia \\ Email: dr-azizghamdi@hotmail.com
}

How to cite this paper: Al-Ghamdi, A.Y. (2018) Antibacterial Activity of Green Synthesis Silver Nanoparticles Using Some Wild Edible Plants Commonly Used in $\mathrm{Al}$ Baha, Saudi Arabia. Advances in Microbiology, 8, 938-949.

https://doi.org/10.4236/aim.2018.812063

Received: November 3, 2018

Accepted: December 14, 2018

Published: December 17, 2018

Copyright $\odot 2018$ by author and Scientific Research Publishing Inc. This work is licensed under the Creative Commons Attribution International License (CC BY 4.0).

http://creativecommons.org/licenses/by/4.0/

(c) (i) Open Access

\begin{abstract}
In the present study, aqueous extract of Cissus rotundifolia (Wild edible plants) was used as a reducing and capping agent in the formation of silver nanoparticles (AgNPs). UV-visible spectroscopy (Uv-Vis) was used to monitor the formation of AgNPs in the aqueous medium. The green-prepared AgNPs investigated using Fourier-transform infrared spectroscopy (FTIR) and X-ray powder diffraction (XRD). The morphology and size of the benign silver nanoparticles were carried out by the transmission electron microscope (TEM) and field emission scanning electron microscope (FE-SEM). The susceptibility of bacteria strains against the green synthesis AgNPs was determined using the disk diffusion method. The microorganisms employed were E. coli, K. pneumoniae, B. cereus, S. aureus, C. lbicans and Aspergillus. The results showed the characteristic surface plasmon resonance peak of the AgNPs appeared at approximately $418-446 \mathrm{~nm}$. XRD revealed peaks at 38.2, 44.16, 64.24 and $77.22 \theta$, and the intensity of these peaks enhanced when using microwave curing compared to ambient temperature. SEM and TEM results showed that the silver nanoparticles have a spherical shape and the particle size for samples is less than $37 \mathrm{~nm}$. FTIR spectroscopy measurements showed the binding of organic compounds on the surface of the silver nanoparticles. The highest antibacterial activity was enhanced with increasing of AgNPs dose and with increasing of extract ration against most of microorganisms.
\end{abstract}

\section{Keywords}

Green Synthesis, AgNPs, FTIR, XRD, SEM-EDX \& TEM, Biological Activity

\section{Introduction}

Wild edible plants are growing freely in the wild habitat without any agricultural 
treatments [1]. These plants are rich in minerals, vitamins, dietary fiber, fatty acids and amino acids [2]. However, the presence of anti-nutritional principles in some species of wild plants, such as phytic acid, tannins, saponins, alkaloids and oxalates, can limit their exploitation [3]. Cissus rotundifolia is a climbing or prostrate shrub found throughout Africa, Egypt and the Arabian Peninsula and is used as a vegetable [4] [5]. C. rotundifolia (Forsk) Vahl is known as a common Arabian Wax Cissus. This wild plant is commonly used as food thickeners and their leaves only are widely consumed after cooking to prepare various dishes according to traditional dietary culture of locals. Tubers of $C$. rotundifolia are added to food as a flavoring agent [6]. Korish [7] evaluated the nutrition of $C$. rotundifolia leaves. They contain an appreciable amount of protein (high level of essential amino acids), fat (about 55\% unsaturated fatty acids), crude fiber and minerals. The anti-nutritional factors: oxalate, phytate, tannins and cyanogenic glycosides, are present at very low concentrations. C. rotundifolia from Africa and Asia showed anti-diabetic [8] as well as anti-parasitic properties [9]. It has minor economic importance as a medicinal plant [10]. An animal study has already shown that these plant materials have hypocholesterolemic activity [11]. In Yemen, this plant is used in many traditional or popular medical applications, such as loss of appetite, anti-malarial, gastrointestinal troubles, skin diseases and burns [12] [13] [14] [15]. Siddiqui et al. [16] used the useless and discarded leaves of $C$. rotundifolia for preparing bio adsorbent to the removal of heavy metal pollutant of water. Al-Mamary [17] reported that C. rotundifolia has significant antioxidant efficiencies that could be attributed to the presence of phenolics.

Nanoparticles of metals have unique properties, such as surface area and particle size, which are mainly different from those of bulk materials [18] [19]. Solar energy systems, optics, catalytic and antibacterial capacities are main applications fields of AgNPs [20]. Recently, many studies conformed that silver nanoparticles (AgNPs) display effective antimicrobial capacity against both gram-positive and gram-negative bacterial strains. Whereas, toxicity and hazard of chemicals, in addition to high cost and power consumption, are the main drawbacks of chemical methods to preparing silver nanoparticles [21]. AgNPs were synthesized using a green, rapid, one-step, cost-effective and environmentally friendly method using Ziziphus Jujuba leaf extract [22]. A bio-synthesis of Ag-NPs using water extract of $M$. pendan was successfully carried out. Whereas, the water soluble flavonoids in the water extract were responsible in the reduction of $\mathrm{Ag}^{+}$to $\mathrm{Ag}^{0}$ [23]. The synthesized silver nanoparticles using autoclave assisted gum extract of neem (Azadirachta indica) are exhibited antibacterial activity against clinical isolates of Salmonella enteritidis and Bacillus cereus [24]. Rajeshkumar [25] investigated the antibacterial activity of biosynthesized silver nanoparticles using the fresh bark extract of Pongamia pinnata against gram positive (Klebsiella planticola) and gram negative (Staphylococcus aureus) bacteria. Khan et al. [26] were attributed the antimicrobial activities of silver nanomaterials to the structural changes in the protein cell wall. Antibacterial tests using four bacteria 
strains showed that the AgNPs/Camomile extract performed five times better compared to pure Camomile extract and AgNPs/Glucose samples [27]. The antibacterial activity of bio capped Ag NPs with leaf extracts of Commiphora caudata shows that these particles have higher inhibitory action for Escherichia coli, Klebsiella pheumoniea, Micrococcus flavus, Pseudomonas aeruginosa, Bacillus subtilis, Bacillus pumilus, Staphylococcus aureus [28].

The current investigation was carried out to screen the antibacterial activity of green synthesis silver nanoparticles using wild edible plants extract against some pathogenic bacterial strains.

\section{Material and Methods}

\subsection{Collection of Plant Materials}

Sample of fresh $C$. rotundifolia leaves were collected from a farm at Al-Mikhwah city, Al Baha region in as shown in Figure 1 . About $1000 \mathrm{~g}$ of plant were washed and rinsed with distilled water. Sample was dried indoor and grinded to fine powder using kitchen blender (grinder of Moulinex blender, $400 \mathrm{~W}$ ) for $2.5 \mathrm{~min}$ at high speed and then stored in plastic bags.

\subsection{Microorganisms}

Bacterial strains were isolated from food samples, which included $E$. coli and

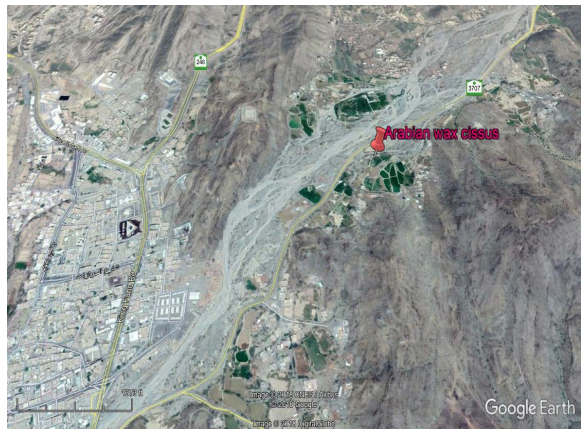

(a)

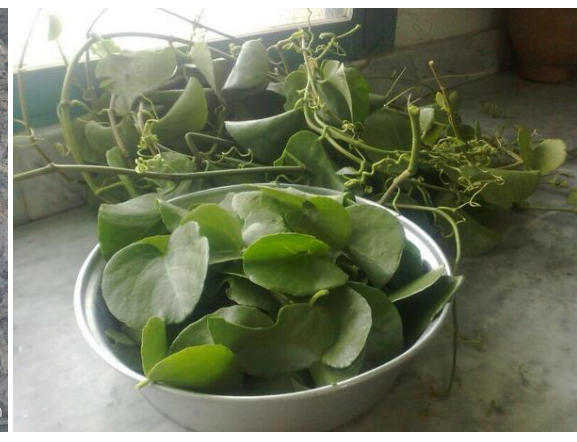

(b)

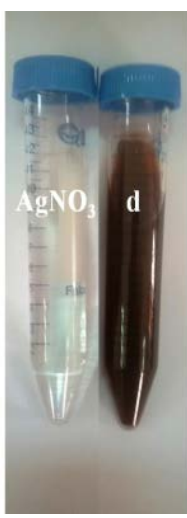

(c)

Figure 1. (a) Google earth image of location of Wild plant (C. rotundifolia), (b) image of Arabian Wax Cissus leaves and (c) AgNPs prepared using aqueous extract of plant. 
Klebsilla (gram negative); Bacillus cereus and Staph aureus (gram positive); Candida (yeast) and Aspirigullus (mold). The strains were kept at $4^{\circ} \mathrm{C}$ on agar slant and sub cultured at $37^{\circ} \mathrm{C}$ for $24 \mathrm{~h}$ on nutrient agar before any susceptibility test.

\subsection{Extraction of Material and Synthesis of Silver Nanoparticles}

$100 \mathrm{~g}$ of powdered sample with $750 \mathrm{ml}$ of deionized water poured into pressure cooker and kept for $2 \mathrm{hr}$ on the hot plate at $350^{\circ} \mathrm{C}$. The solid residues were removed by filtration and the extract kept in refrigerator to use time [29]. 99.9\% pure $\mathrm{AgNO}_{3}$ was purchased from Sigma-Aldrich, Cairo, Egypt. Table 1 shows the different conditions of green synthesis of AgNPs. A $20 \mathrm{mM}$ solution of Ag$\mathrm{NO}_{3}$ was prepared for production of AgNPs. Green reduction of $\mathrm{Ag}^{+}$was monitored by visual observation and UV-visible spectroscopy.

\subsection{Antimicrobial Assay}

The antimicrobial activity of AgNPs was investigated by the disk diffusion method. The pure cultures of each strain were swabbed uniformly on the individual plates using sterile cotton at $35^{\circ} \mathrm{C}$ on a rotary shaker at $200 \mathrm{RPM}$. Sterile filter paper discs (5 $\mathrm{mm}$ in diameter) impregnated with 25, 50, 100, 150 and $200 \mu \mathrm{L}$ of the samples of silver nanoparticles solution then sited on the surface of these agar plates. The plates were then incubated at $37^{\circ} \mathrm{C}$ for bacterial growth after which growth was determined by measuring the diameter of the inhibition zone $(\mathrm{mm})$ using a digital caliper. Each extract was analyzed in triplicate, the mean values are presented. Tetracycline $(30 \mathrm{mg} / \mathrm{disc})$ was used as a gram-positive control.

\subsection{Characterization Tools}

The reduction of silver ions into silver nanoparticles monitored by UV-visible spectroscopy (SHIMADZU MODELUV 1800, Japan) at a wavelength of 350 $700 \mathrm{~nm}$. A diffractometer XRD thin film PANalytical X pert PRO, Cu target, wave length $1.54 \mathrm{~A}, 45 \mathrm{kV}, 40 \mathrm{~mA}$ made in Holland was used to determine the crystallinity of prepared AgNPs. Scanning electron microscopy (SEM) examination was performed using JEOL JSM 6360 DLA, Japan, at $30 \mathrm{kV}$, and the SEM-EDX analysis was performed by FEI Company, Quanta FEG250, Holland. Transmission electron microscopy image were taken using a Hitachi, H-800 TEM. TEM

Table 1. Different concentration of silver nitrate and Arabian Wax Cissus extract used for green synthesis of AgNPs.

\begin{tabular}{ccccc}
\hline Sample & $\mathrm{AgNO}_{3}, 20 \mathrm{mM}, \mathrm{ml}$ & extract, $\mathrm{ml}$ & $\mathrm{R}, \%$ & Temperature \\
\hline $\mathrm{a}$ & 90 & 10 & 10 & ambient \\
b & 80 & 20 & 20 & ambient \\
c & 70 & 30 & 30 & ambient \\
d & 60 & 40 & 40 & ambient \\
\hline
\end{tabular}


samples were prepared by placing drops of aqueous dispersion of AgNPs in distilled water on 200 mesh carbon coated copper grids and dried at ambient conditions for 10 to $12 \mathrm{~h}$. The FT-IR spectra of the products recorded on a JASCO Asia Portal - FT/IR-6300 Spectrometer using the KBr pellet method.

\section{Results and Discussion}

\subsection{Characterizations of AgNPs}

Green reduction of $\mathrm{Ag}^{+}$by $C$. rotundifolia extract was monitored by observing the colour of silver solutions that changed from colourless, to yellow, brown and then reddish brown as evidence of silver ion reduction, Figure 1(c), increasing the silver nanoparticles concentration and changing the particle morphology. It was observed that the colour started to change after $0.5 \mathrm{~min}$. and reached a maximum absorption capacity of UV after $7 \mathrm{~min}$.

This period decreased with increasing the $C$. rotundifolia extract content. In addition, the UV-Vis spectroscopy investigation of the prepared AgNPs showed that the size and shape of AgNPs influence the shape and position of the UV-Vis absorption peaks from plasmon resonance. The UV-Vis absorption spectra of the synthesized AgNPs at ambient temperatures with time intervals up to $3 \mathrm{~h}$ are shown in Figures 2(a)-(d). The appearance of a strong peak at $437 \mathrm{~nm}$ indicated the formation of AgNPs that related to its surface plasmon resonance phenomena [30]. As shown in Figures 2(a)-(d), the absorbance value for AgNPs increased with an increase in $C$. rotundifolia extract ratio and indicated a higher concentration of AgNPs produced, which was due to the availability of more reducing bio-molecules in $C$. rotundifolia extract. The SPR peaks at a lower substitution of $C$. rotundifolia extract 20:80 (v/v) were broad band whereas with a higher substitution ratio the SPR peaks became sharper and narrower. The intensity of this absorption band increased with time with a slight shift to $441 \mathrm{~nm}$. The organic compounds in the C. rotundifolia extract contain numerous functional groups that can interact with silver to form a complex. Furthermore, the cleavage of $\mathrm{C}-\mathrm{C}$ bonds of organic molecules released electrons required for the reduction of Ag. When the complex compound $\mathrm{Ag}^{+-}$C. rotundifolia was reduced to $\mathrm{Ag}^{0-}$ cissus, the organic molecules endow AgNPs with excellent dispersibility.

Figure 3 shows XRD patterns of the green synthesized AgNPs. The distinct diffraction bands at approximately 37.97, 44.29, 64.38 and $77.392 \theta$ correspond to (111), (200), (220) and (311), respectively, were matched to planes of a face-centred cubic lattice of silver (ICSD No. 01-071-4613), which confirm the crystalline structure of prepared AgNPs. The extra peaks near 22.5, 26.2, 29.2 and $32.02 \theta$ are due to the presence of organic compounds on the surface of AgNPs. The intensity of the peak at the (111) plane was greater than the other peaks, suggesting that this plane was the predominant one. According to Scherrer's formula, the average sizes of AgNPs synthesized by $C$. rotundifolia leaf extracts at room temperature is $28 \mathrm{~nm}$ [31] [32]. 


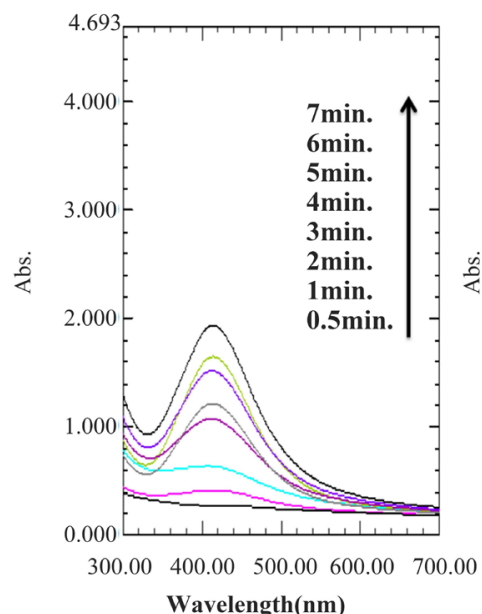

(a)

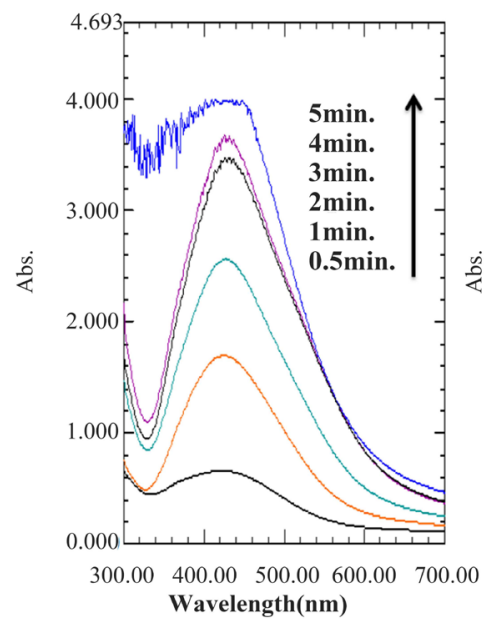

(c)

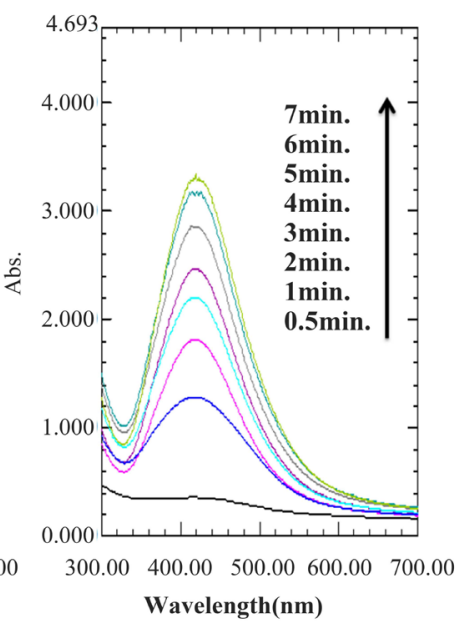

(b)

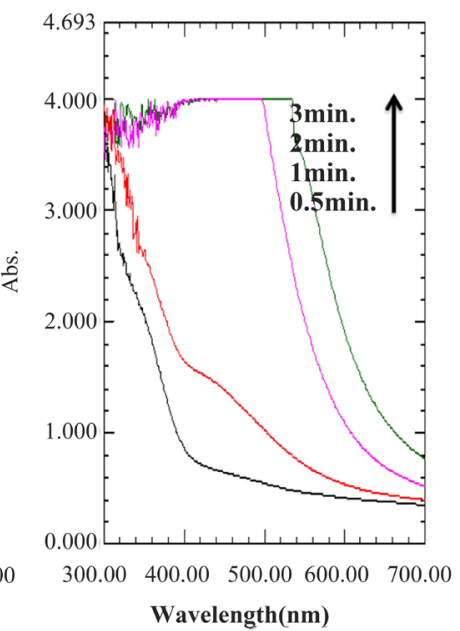

(d)

Figure 2. Absorption spectra of prepared AgNPs at ambient temperature (a) 10\%, (b) $20 \%$, (c) $30 \%$ and (d) $40 \%$ of Cissus leaf extract.

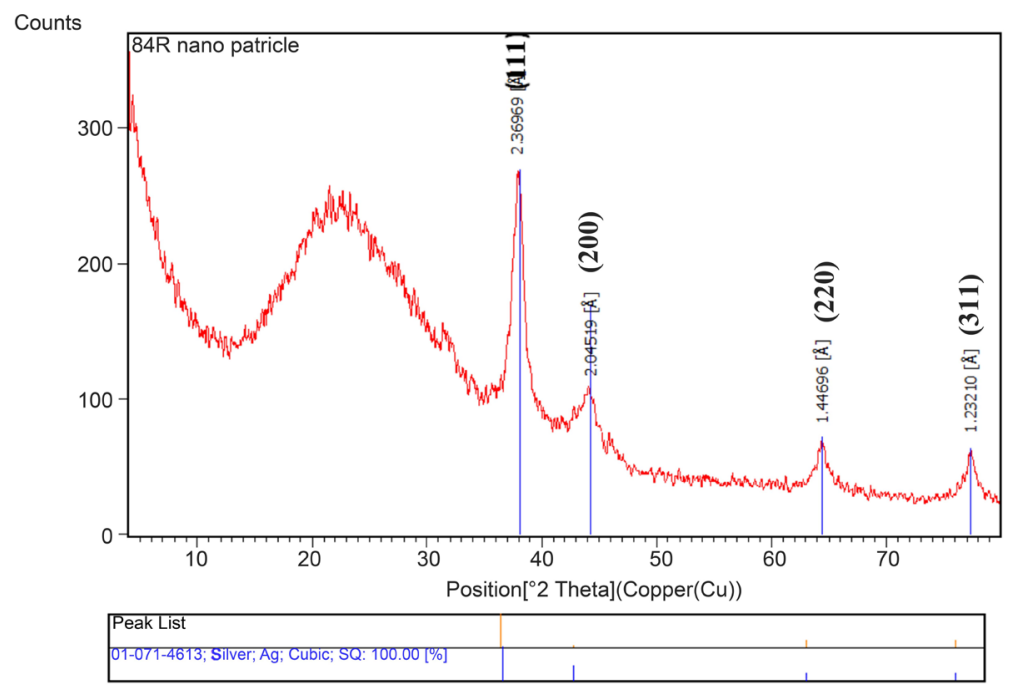

Figure 3. XRD patterns of synthesized AgNPs at ambient temperature (d) $40 \%$ of Cissus leaf extract. 
The presence of organic compounds of $C$. rotundifolia extract on the surface of the nanoparticles was investigated using FTIR. The FTIR spectra of silver nanoparticles prepared with 40:60 (v/v) leaf extract: $\mathrm{Ag}^{+}(\mathrm{d})$ at ambient is shown in Figure 4 . The band at $3432 \mathrm{~cm}^{-1}$ is attributed to the hydroxyl group of organic compounds, the small bands appearing at 2927 and $2852 \mathrm{~cm}^{-1}$ may be due to $\mathrm{C}-\mathrm{H}$ stretching of vibration of the $-\mathrm{CH}_{2}$ group from the aliphatic chains, and a relatively strong band can be noted at $2065 \mathrm{~cm}^{-1}$ due to $\mathrm{CN}$ stretching vibration [33]. Additionally, the band at $1635 \mathrm{~cm}^{-1}$ is related to stretching of the carbonyl groups and bands at $1384 \mathrm{~cm}^{-1}$ and $1106 \mathrm{~cm}^{-1}$ related to the carboxylic groups. These absorption bands indicate the absorption of different organic.

Figure 5 shows SEM images of the nanoparticles synthesized with 40:60 (v/v) BLE leaf extract: $\mathrm{Ag}^{+}$( $\mathrm{d}$ sample) at ambient. Mostly spherical and nearspherical shapes were observed for AgNPs in the $20-40 \mathrm{~nm}$ size range. TEM analysis gives actual information about the morphology of the surface of the AgNPs.

TEM images of the prepared AgNPs with different magnifications are shown in Figures 6(a)-(c). They clearly show the formation of the best AgNPs with spherical and oval shapes in the size range of $22-38 \mathrm{~nm}$. These perfect particle sizes with various shapes of AgNPs may be related to different components of the plant extract [34]. ATEM image of AgNPs is shown in Figure 6(d). It clearly shows a lattice spacing of $0.21 \mathrm{~nm}$ related to the (111) plane of Ag that matches with the XRD pattern. The polycrystalline nature of prepared silver nanoparticles was confirmed by SAED, Figure 6(e), as the FCC structure of silver [35]. Furthermore, EDX analysis confirmed the presence of silver as a single element.

\subsection{Antimicrobial Activity of Green Prepared AgNPs}

Antibacterial activities of the prepared AgNPs using extract of $C$. rotundifolia against the tested organisms are shown in Table 2. All the AgNPs samples tested

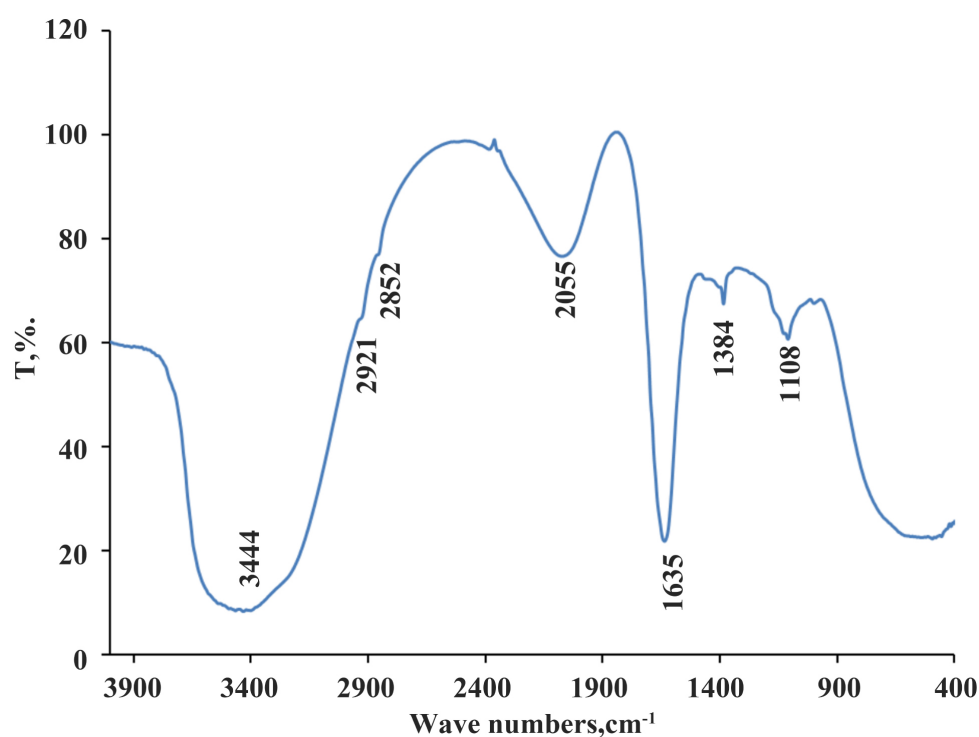

Figure 4. FTIR spectra of synthesized AgNPs at ambient temperature (d sample) $40 \%$ of C. rotundifolia leaf extract. 


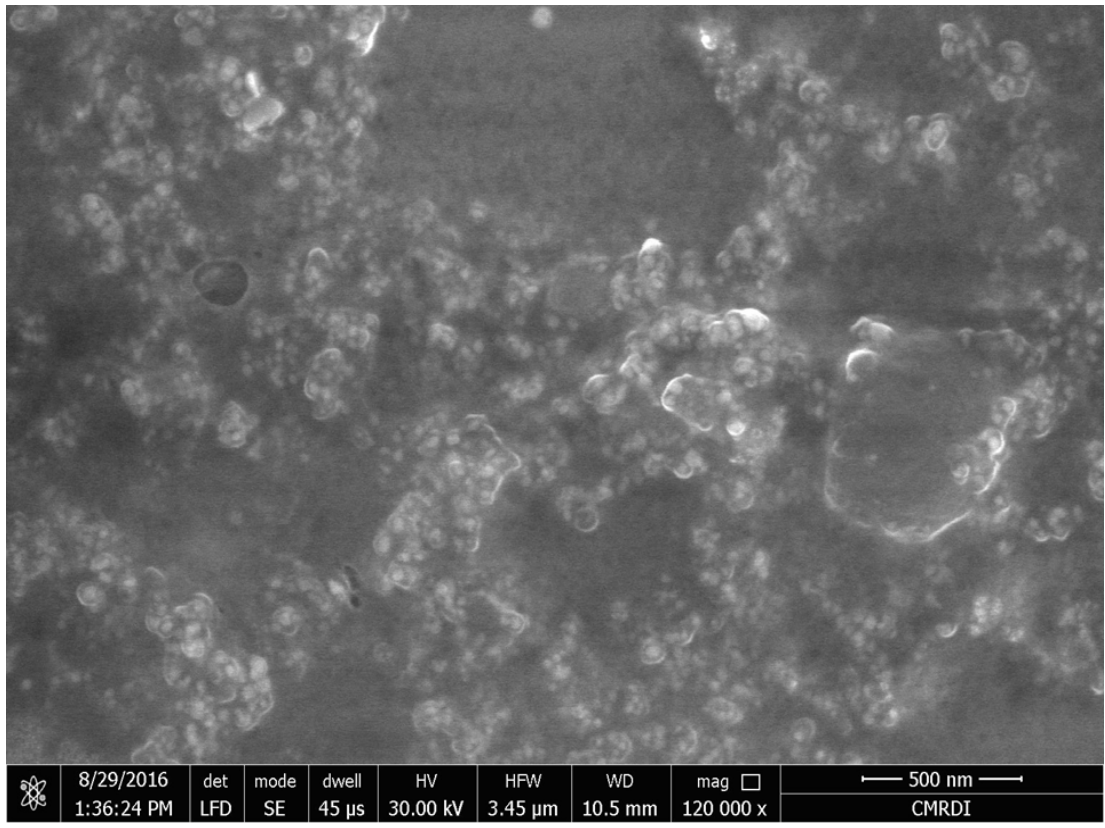

Figure 5. (a) FESEM micrograph of synthesized AgNPs at ambient temperature (d sample) $40 \%$ of $C$. rotundifolia leaf extract.
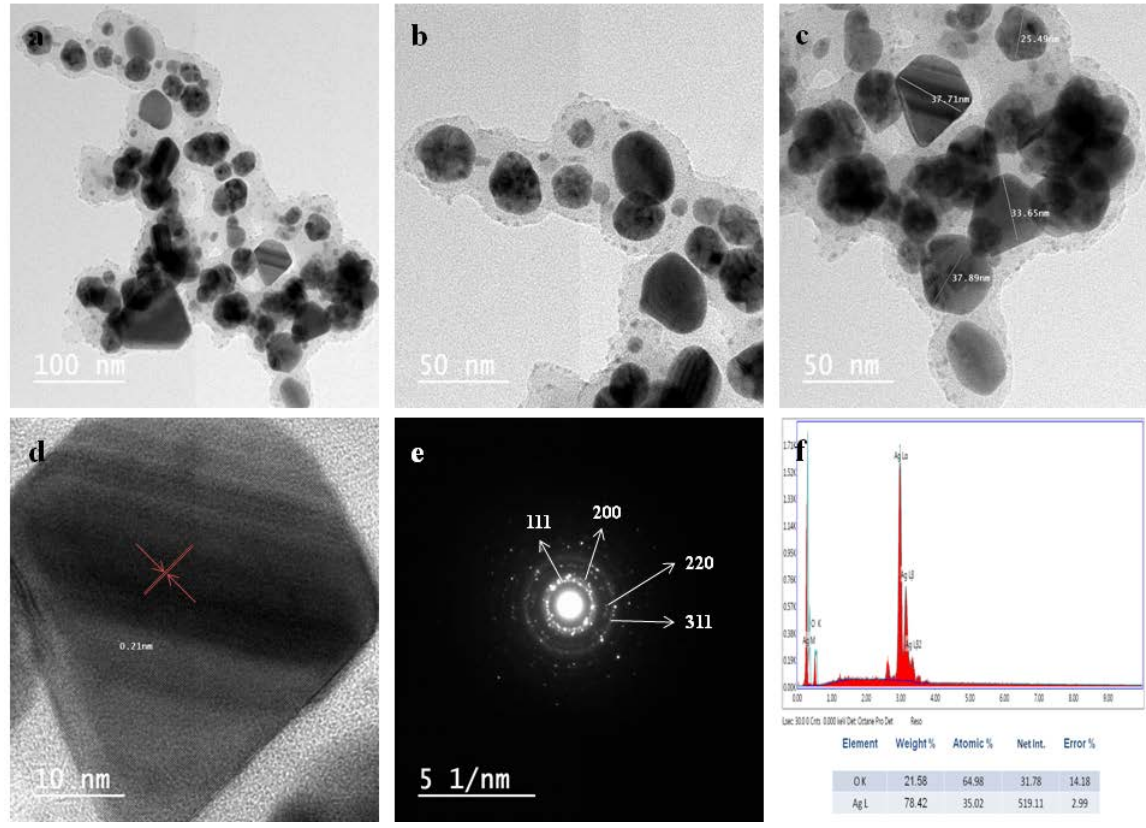

Figure 6. (a-d) HRTEM images of synthesized AgNPs at ambient temperature (d sample) $40 \%$ of $C$. rotundifolia leaf extract, (e) SADE image, (f) EDX Spectrum.

showed antibacterial activity, however, the $C$. rotundifolia extract differ in its activities against the micro-organisms tested. As seen in Table 2, the inhibition zone area increased with a higher dose of AgNPs from 25 to $200 \mu \mathrm{ml}$. The highest antibacterial activity was observed with increasing ratio of plant extract (d sample, 40\%) against E. coli, K. Pneumoniae and B. Cereus. This is clearly attributed to antimicrobial efficiency of AgNPs, and not to the organic compounds 
Table 2. Antimicrobial activity of green synthesis AgNPs against different microorganisms.

\begin{tabular}{|c|c|c|c|c|c|c|c|c|c|c|c|c|c|c|}
\hline Sample & $\mathrm{b}$ & c & $\mathrm{d}$ & b & c & $\mathrm{d}$ & $\mathrm{b}$ & c & $\mathrm{d}$ & $\mathrm{b}$ & c & $\mathrm{d}$ & \multicolumn{2}{|c|}{ Blank } \\
\hline Dose, $\mu \mathrm{L}$ & & 25 & & & 50 & & & 100 & & & 200 & & -ve ZOI & +ve ZOI \\
\hline Micro organism & & & & & & & Zone of & nhibitic & & & & & & \\
\hline E. coli & 0 & 0 & 0 & 14.80 & 15.08 & 17.00 & 12.39 & 16.52 & 20.34 & 12.3 & 14.07 & 22.67 & 0 & 22.75 \\
\hline$K$. pneumoniae & 0 & 12.35 & 13.81 & 15.60 & 17.05 & 26.18 & 14.73 & 18.8 & 20.7 & 16.27 & 23.92 & 27.31 & 0 & 20.61 \\
\hline B. Cereus & 0 & 0 & 0 & 10.33 & 12.34 & 18.23 & 17.71 & 22.18 & 26.37 & 22.39 & 23.21 & 29.34 & 0 & 25.5 \\
\hline S. aureus & 0 & 0 & 11.93 & 15.71 & 16.90 & 18.47 & 15.67 & 16.83 & 19.08 & 15.81 & 19.92 & 20.2 & 0 & 27.44 \\
\hline C. lbicans & 0 & 0 & 0 & 12.64 & 12.09 & 12.93 & 11.27 & 14.16 & 16.1 & 17.27 & 20.83 & 22.24 & 0 & 0 \\
\hline Aspergillus & 0 & 0 & 0 & 13.54 & 11.67 & 11.09 & 11.6 & 15.24 & 15.77 & 21.42 & 22.42 & 23.56 & 0 & 0 \\
\hline
\end{tabular}

*Values are mean inhibition zone $(\mathrm{mm}) \pm$ S.D of three replicates.

in the extract. The mechanism of AgNPs as an antimicrobial is not understood, but many studies suggest that it occurs through the interaction of silver nanoparticles with the DNA of microorganisms, forming free radicals and destructuring the cell walls [36] [37].

\section{Conclusion}

From the outcomes of this study, we can conclude that silver nanoparticles can be prepared using an aqueous extract of $C$. rotundifolia leaf. The stability of biosynthetic silver nanoparticles was monitored for up to six months. The prepared AgNPs showed antimicrobial activity against E. coli, K. pneumoniae, B. cereus, $S$. aureus, $C$. lbicans and Aspergillus and it increased with increasing the dose of plant extract.

\section{Acknowledgements}

Thanks to the help of Deanship of Scientific Research at Al-Baha University, KSA. This work was financial supported by Deanship of Scientific Research at Al-Baha University, Kingdome of Saudi Arabian (48/1438).

\section{Conflicts of Interest}

The author declares no conflicts of interest regarding the publication of this paper.

\section{References}

[1] Beluhan, S. and Ranogajec, A. (2011) Chemical Composition and Non-Volatile Components of Croatian Wild Edible Mushrooms. Food Chemistry, 124, 1076-1082. https://doi.org/10.1016/j.foodchem.2010.07.081

[2] Barros, L., Carvalho, A.M. and Ferreira, I.C. (2010) Leaves, Flowers, Immature Fruits and Leafy Flowered Stems of Malva sylvestris. A Comparative Study of the Nutraceutical Potential and Composition. Food and Chemical Toxicology, 48, 1466-1472. https://doi.org/10.1016/j.fct.2010.03.012 
[3] Lachumy, S.J.T., Sasidharan, S., Sumathy, V. and Zuraini, Z. (2010) Pharmacological Activity, Phytochemical Analysis and Toxicity of Methanol Extract of Etlingera elatior (Torch Ginger) Flowers. Asian Pacific Journal of Tropical Medicine, 3, 769-774. https://doi.org/10.1016/S1995-7645(10)60185-X

[4] Abuodha, J.O.Z., Musila, W.M. and van der Hagen, H. (2003) Floristic Composition and Vegetation Ecology of the Malindi Bay Coastal Dune Field, Kenya. Journal of Coastal Conservation, 9, 97. https://doi.org/10.1652/1400-0350(2003)009[0097:FCAVEO]2.0.CO;2

[5] Sarvalingam, A., Rajendran, A., Sivalingam, R. and Jayanthi, P. (2013) Occurrence of Cissus rotundifolia (Forsk) Vahl-Vitaceae in Peninsular India. Academic Journal of Plant Sciences, 6, 117-118.

[6] Johns, T. and Kokwaro, J.O. (1991) Food Plants of the Luo of Siaya District, Kenya. Economic Botany, 45, 103-113. https://doi.org/10.1007/BF02860055

[7] Korish, M. (2016) Nutritional Evaluation of Wild Plant Cissus rotundifolia. Italian Journal of Food Science, 28, 43-49.

[8] Onyechi, U.A., Judd, P.A. and Ellis, P.R. (1998) African Plant Foods Rich in Non-Starch Polysaccharides Reduce Postprandial Blood Glucose and Insulin Concentrations in Healthy Human Subjects. British Journal of Nutrition, 80, 419-428.

[9] Alzoreky, N.S. and Nakahara, K. (2003) Antibacterial Activity of Extracts from Some Edible Plants Commonly Consumed in Asia. International Journal of Food Microbiology, 80, 223-230. https://doi.org/10.1016/S0168-1605(02)00169-1

[10] Balogun, A.M. and Fetuga, B.L. (1986) Chemical Composition of Some Underexploited Leguminous Crop Seeds in Nigeria. Journal of Agricultural and Food Chemistry, 34, 189-192. https://doi.org/10.1021/jf00068a008

[11] Bell, S., Onyechi, U.A., Judd, P.A., Ellis, P.R. and Ross-Murphy, S.B. (1993) An Investigation of the Effects of Two Indigenous African Foods, Detarium microcarpum and Cissus rotundifolia, on Rat Plasma Cholesterol Levels. Proceedings of the $\mathrm{Nu}$ trition Society, 52, 372a.

[12] Alzoreky, N. and Nakahara, K. (2001) Antioxidant Activity of Some Edible Yemeni Plants Evaluated by Ferrylmyoglobin/ABTS* + Assay. Food Science and Technology Research, 7, 141-144. https://doi.org/10.3136/fstr.7.141

[13] Ali, A.A., Al-Rahwi, K. and Lindequist, U. (2004) Some Medicinal Plants Used in Yemeni Herbal Medicine to Treat Malaria. African Journal of Traditional, Complementary and Alternative Medicines, 1, 72-76. https://doi.org/10.4314/ajtcam.vli1.31097

[14] Alshawsh, M.A., Mothana, R.A., Al-Shamahy, H.A., Alsllami, S.F. and Lindequist, U. (2009) Assessment of Antimalarial Activity against Plasmodium falciparum and Phytochemical Screening of Some Yemeni Medicinal Plants. Evidence-Based Complementary and Alternative Medicine, 6, 453-456.

https://doi.org/10.1093/ecam/nem148

[15] Suleman, S., Tufa, T.B., Kebebe, D., Belew, S., Mekonnen, Y., Gashe, F., et al. (2018) Treatment of Malaria and Related Symptoms Using Traditional Herbal Medicine in Ethiopia. Journal of Ethnopharmacology, 213, 262-279. https://doi.org/10.1016/j.jep.2017.10.034

[16] Siddiqui, S., Otaif, K. and Laskar, M.A. (2016) Characterization and Efficacy of a New Generation Scavenger of Heavy Metal Pollutant: A Green Method of Remediation of Wastewater. International Journal of Environmental Science and Technology, 13, 2951-2960. https://doi.org/10.1007/s13762-016-1119-8 
[17] Al-Mamary, M.A. (2002) Antioxidant Activity of Commonly Consumed Vegetables in Yemen. Malaysian Journal of Nutrition, 8, 179-189.

[18] Abdel-Mohsen, A.M., Hrdina, R., Burgert, L., Krylová, G., Abdel-Rahman, R.M., Krejčová, A., Beneš, L., et al. (2012) Green Synthesis of Hyaluronan Fibers with Silver Nanoparticles. Carbohydrate Polymers, 89, 411-422. https://doi.org/10.1016/j.carbpol.2012.03.022

[19] Kumar, D.A., Palanichamy, V. and Roopan, S.M. (2014) Green Synthesis of Silver Nanoparticles Using Alternanthera dentata Leaf Extract at Room Temperature and Their Antimicrobial Activity. Spectrochimica Acta Part A: Molecular and Biomolecular Spectroscopy, 127, 168-171. https://doi.org/10.1016/j.saa.2014.02.058

[20] El-Gammal, O.A. (2010) Synthesis, Characterization, Molecular Modeling and Antimicrobial Activity of 2-(2-(ethylcarbamothioyl) hydrazinyl)-2-oxo-N phenylacetamide Copper Complexes. Spectrochimica Acta Part A: Molecular and Biomolecular Spectroscopy, 75, 533-542. https://doi.org/10.1016/j.saa.2009.11.007

[21] Sana, S.S., Badineni, V.R., Arla, S.K. and Boya, V.K.N. (2015) Eco-Friendly Synthesis of Silver Nanoparticles Using Leaf Extract of Grewia flaviscences and Study of Their Antimicrobial Activity. Materials Letters, 145, 347-350. https://doi.org/10.1016/j.matlet.2015.01.096

[22] Gavade, N.L., Kadam, A.N., Suwarnkar, M.B., Ghodake, V.P. and Garadkar, K.M. (2015) Biogenic Synthesis of Multi-Applicative Silver Nanoparticles by Using Ziziphus jujuba Leaf Extract. Spectrochimica Acta Part A: Molecular and Biomolecular Spectroscopy, 136, 953-960. https://doi.org/10.1016/j.saa.2014.09.118

[23] Zuas, O., Hamim, N. and Sampora, Y. (2014) Bio-Synthesis of Silver Nanoparticles Using Water Extract of Myrmecodia pendan (Sarang Semut Plant). Materials Letters, 123, 156-159. https://doi.org/10.1016/j.matlet.2014.03.026

[24] Velusamy, P., Das, J., Pachaiappan, R., Vaseeharan, B. and Pandian, K. (2015) Greener Approach for Synthesis of Antibacterial Silver Nanoparticles Using Aqueous Solution of Neem Gum (Azadirachta indica L.). Industrial Crops and Products, 66, 103-109. https://doi.org/10.1016/j.indcrop.2014.12.042

[25] Rajeshkumar, S. (2016) Synthesis of Silver Nanoparticles Using Fresh Bark of Pongamia pinnata and Characterization of Its Antibacterial Activity against Gram Positive and Gram Negative Pathogens. Resource-Efficient Technologies, 2, 30-35. https://doi.org/10.1016/j.reffit.2016.06.003

[26] Khan, M.N., Khan, T.A., Khan, Z. and Al-thabaiti, S.A. (2015) Green Synthesis of Biogenic Silver Nanomaterials Using Raphanus sativus Extract, Effects of Stabilizers on the Morphology, and Their Antimicrobial Activities. Bioprocess and Biosystems Engineering, 38, 2397-2416. https://doi.org/10.1007/s00449-015-1477-5

[27] Parlinska-Wojtan, M., Kus-Liskiewicz, M., Depciuch, J. and Sadik, O. (2016) Green Synthesis and Antibacterial Effects of Aqueous Colloidal Solutions of Silver Nanoparticles Using Camomile Terpenoids as a Combined Reducing and Capping Agent. Bioprocess and Biosystems Engineering, 39, 1213-1223. https://doi.org/10.1007/s00449-016-1599-4

[28] Venugobal, J. and Anandalakshmi, K. (2016) Green Synthesis of Silver Nanoparticles Using Commiphora caudata Leaves Extract and the Study of Bactericidal Efficiency. Journal of Cluster Science, 27, 1683-1699. https://doi.org/10.1007/s10876-016-1032-9

[29] Parekh, J. and Chanda, S. (2007) In Vitro Antimicrobial Activity and Phytochemical Analysis of Some Indian Medicinal Plants. Turkish Journal of Biology, 31, 53-58.

[30] Das, J., Das, M.P. and Velusamy, P. (2013) Sesbania grandiflora Leaf Extract Me- 
diated Green Synthesis of Antibacterial Silver Nanoparticles against Selected Human Pathogens. Spectrochimica Acta Part A: Molecular and Biomolecular Spectroscopy, 104, 265-270. https://doi.org/10.1016/j.saa.2012.11.075

[31] Reddy, T.R.K. and Kim, H.J. (2016) Facile Synthesis of Silver Nanoparticles and Its Antibacterial Activity against Escherichia coli and Unknown Bacteria on Mobile Phone Touch Surfaces/Computer Keyboards. Applied Physics A, 122, 652. https://doi.org/10.1007/s00339-016-0193-6

[32] Ibrahim, H.M. (2015) Green Synthesis and Characterization of Silver Nanoparticles Using Banana Peel Extract and Their Antimicrobial Activity against Representative Microorganisms. Journal of Radiation Research and Applied Sciences, 8, 265-275. https://doi.org/10.1016/j.jrras.2015.01.007

[33] de Matos, R.A. and Courrol, L.C. (2014) Saliva and Light as Templates for the Green Synthesis of Silver Nanoparticles. Colloids and Surfaces A: Physicochemical and Engineering Aspects, 441, 539-543.

https://doi.org/10.1016/j.colsurfa.2013.10.009

[34] Sau, T.K. and Rogach, A.L. (2010) Nonspherical Noble Metal Nanoparticles: Colloid-Chemical Synthesis and Morphology Control. Advanced Materials, 22, 1781-1804. https://doi.org/10.1002/adma.200901271

[35] Tai, Y.L. and Yang, Z.G. (2011) Fabrication of Paper-Based Conductive Patterns for Flexible Electronics by Direct-Writing. Journal of Materials Chemistry, 21, 5938-5943. https://doi.org/10.1039/c0jm03065a

[36] Kim, J.S., Kuk, E., Yu, K.N., Kim, J.H., Park, S.J., Lee, H.J., Kim, Y.K., et al. (2007) Antimicrobial Effects of Silver Nanoparticles. Nanomedicine: Nanotechnology, Biology and Medicine, 3, 95-101. https://doi.org/10.1016/j.nano.2006.12.001

[37] Kim, S.H., Lee, H.S., Ryu, D.S., Choi, S.J. and Lee, D.S. (2011) Antibacterial Activity of Silver-Nanoparticles against Staphylococcus aureus and Escherichia coli. Korean Journal of Microbiology and Biotechnology, 39, 77-85. 